\title{
Offsite Manufacturing: A Survey on the Current Status and Risks of Offsite Construction in Iran
}

\author{
Arman Hashemi \\ Centre for Sustainable Development, Department of Engineering, University of Cambridge, Cambridge CB2 1PZ, UK
}

\begin{abstract}
Iran needs around 1.5 million residential homes to be constructed annually to answer its cumulative demand by 2025 . Given the current situation of the Iranian construction industry, it seems almost impossible to achieve this objective by using traditional methods of construction alone. Offsite manufacturing (OSM) can potentially increase the housing output in Iran thanks to its advantages over traditional methods of construction. However, OSM imposes a different set of risks which should be studied in the Iranian context. This study aims to investigate the readiness of the Iranian construction industry if offsite methods were to be introduced to the country in large industrial scales. To this end, a questionnaire survey was conducted to identify the risks and required actions in order to achieve successful application of these methods. Several subjects including costs, practicality, design and construction processes, demand, governmental policies, technology, and sustainability issues were investigated as the core research areas. The results revealed that, considering the current situations, it would be highly risky to introduce offsite methods of construction to Iran. Research findings highlight some key areas including design and construction processes, economies of scale, governmental supports, and education, which should be addressed to mitigate the identified risks.
\end{abstract}

Key words: Offsite construction, offsite manufacturing, prefabrication, construction technology, housing, Iranian construction industry.

\section{Nomenclature}

\begin{abstract}
Offsite "Offsite is a term used to describe spectrum of construction applications where buildings, structures or parts are manufactured and assembled remote from building site prior to installation in their final position, in other words, moving operations that are traditionally completed onsite to a manufacturing environment" [1]. Offsite construction is also known as prefabrication, modular construction, offsite manufacturing/ assembly/production/fabrication, system building, and industrialized construction [2-5]

Panel Panel systems comprise walls, floors and roofs systems that are made from flat, pre-engineered panels and are assembled onsite in order to form a box/room $[1,5,6]$

Volumetric Also known as modular construction, volumetric systems systems comprise three-dimensional units which are completed in the factory and transported to the site to be assembled $[1,5,6]$

Pods Prefabricated volumetric pod, fully factory finished internally complete with building services. Examples include bath and kitchen pods $[1,5]$
\end{abstract}

Corresponding author: Arman Hashemi, Ph.D., research fields: architectural design/engineering, offsite construction and energy efficiency in building. E-mail: ahashemi@eng.cam.ac.uk.
Hybrid systems (semi-volu panel systems $[1,5,6]$ metric)

\section{Introduction}

Iran needs over a million residential units (Fig. 1) to be constructed annually to answer its current housing demand [7, 8]. In 2009, it was estimated that 24 million houses were required to be constructed in Iran by 2025 [9]. This means an annual output of 1.5 million residential homes during a period of 16 years. It seems almost impossible to achieve this objective by using traditional methods of construction alone (Fig. 2). For this and several other reasons, the Iranian Government has been trying to encourage the construction industry to increase the share of innovative methods of construction to escalate the housing output.

Many experts believe that the only solution for the current Iranian housing crisis is industrialization 


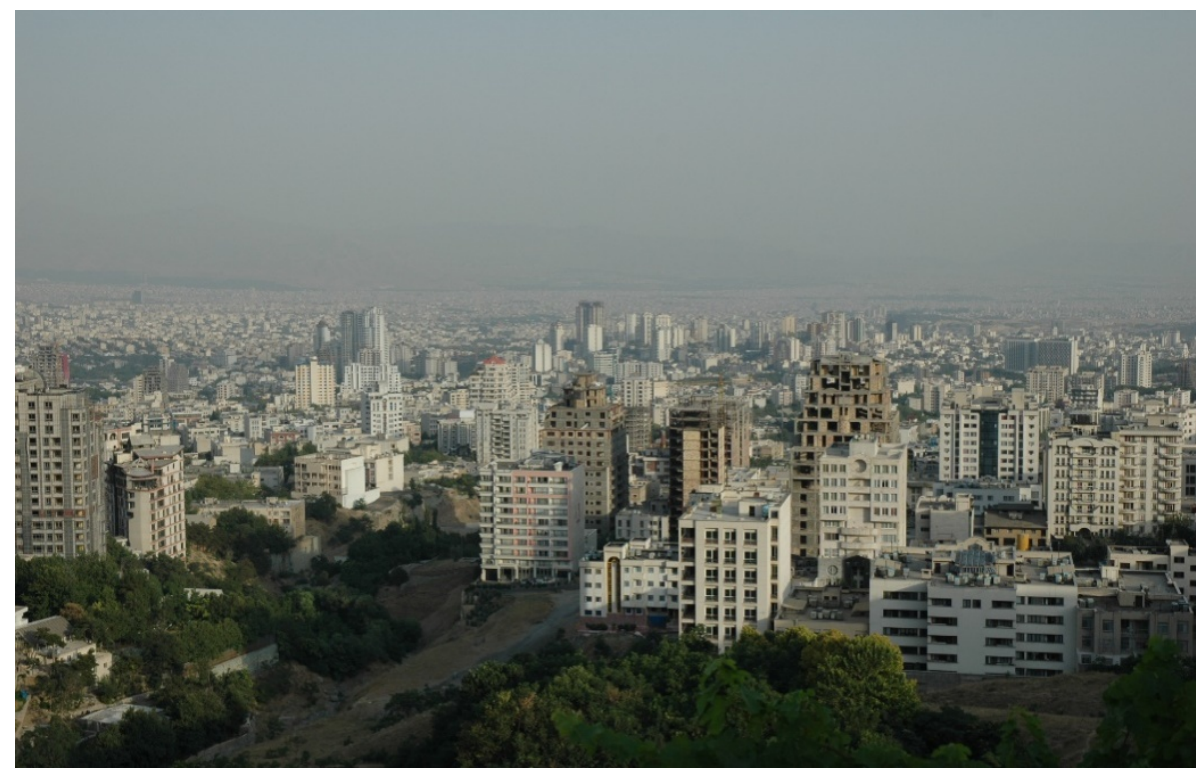

Fig. 1 A view of Tehran from the northern mountains.

Source: the author.

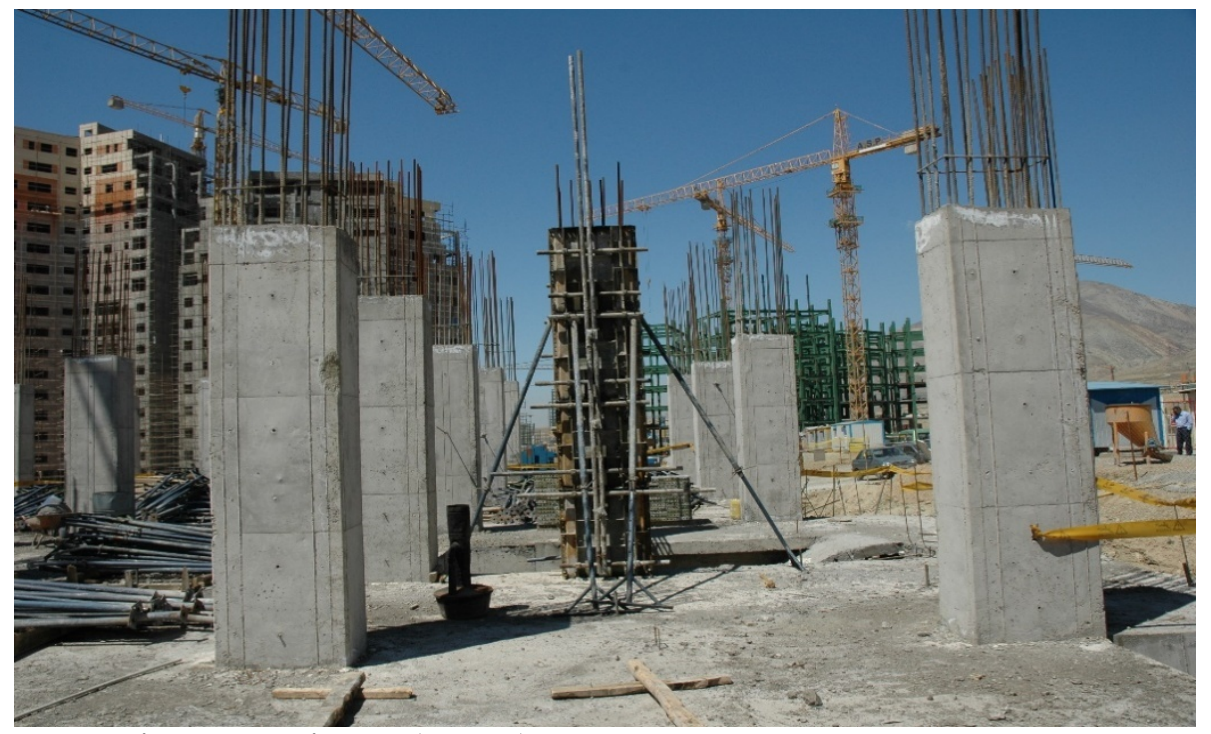

Fig. 2 Prevailing construction methods in Iran (Tehran).

Source: the author.

[10-14]. This was, while in 2008, less than $3 \%$ of buildings that were built using industrial methods [15]. The aim of the Iranian Government was to increase the share of industrialized methods to $20 \%$ by the end of the Fifth National Development Plan in 2013 $[15,16]$. It was not clear as to what extent this objective had been achieved.

Yet, due to the geographical diversity of Iran and economic, cultural, and technical issues, heavy industrialization is far from appropriate. Many studies support this view $[17,18]$ and some disagree [19].

Some support the theory of offsite construction to increase housing output in Iran [14-20] thanks to the advantages of offsite methods over traditional methods of construction [1, 21-24]. Others believe that both modern and traditional sectors of the construction industry should develop more [25]. Various reasons, such as small scale of projects, market fluctuations, extra costs, and use of un-skilled labor, and limited knowledge of stakeholders about advantages, 
disadvantages, and risks of such methods have been suggested as important barriers toward broader application of innovative methods of construction in Iran $[17,26]$.

Some studies indicate that it may be necessary to alter the legislations [27, 28] and skill sets [12] to introduce changes to the building industry. Other studies argue that construction management is the major problem in Iran [29].

Much more in-depth research is required in the area of construction industrialization in Iran as the available literature in this area is very limited and Iran is currently relying on other countries' research in this field. To this end, a questionnaire was designed to evaluate the current situation of offsite methods and the level of knowledge and attitudes of Iranian architects (as one of the key stakeholders) toward such methods of construction. The ultimate objective is to investigate as to how ready Iranian architects would be if offsite methods were to be introduced in large industrial scales to Iran. In other words, the questionnaire has been designed to undertake a risk assessment to evaluate and identify the required actions in order to have successful application of offsite methods of construction in Iran. The results reveal several important issues which should be considered prior to any attempts to introducing offsite method of construction to Iran.

\section{Methodology}

This study reports on the results of a questionnaire designed to investigate the current situation of offsite construction in Iran. The questionnaire was distributed in Tehran, capital city of Iran. Architects were considered as the target research groups given their high influence on design and selection of construction methods in Iran. The design, distribution, and analyzing processes of the questionnaire are explained in the followings sections.

\subsection{Questionnaire Objectives and Design}

Several criteria are involved throughout the design and construction processes when considering a method of construction. Six headings and 31 subheadings were defined as the key criteria when considering a method of construction. This was based on the findings of the available literature, similar questionnaires, including a survey by the Commission for Architecture and Built Environment [30], discussions, and interviews with Iranian and British architects. The identified criteria are as follows:

(1) cost issues: total costs; speed of construction; quality of products; size of projects; ease of future selling; project management during design and construction;

(2) practicality issues: previous experience; skilled labor requirement; machinery availability; availability of details/information; availability of experienced contractors; availability of products in the market; climate/weather dependency; ease of construction (e.g., less complex details);

(3) design issues: design quality; flexibility; cultural issues/social acceptance; client preferences; aesthetic matters;

(4) technical issues: sound resistance; U-value; contract type; resistance in natural disasters (e.g., earthquake);

(5) governmental issues: planning/building approval; governmental supports; insurance; mortgage;

(6) sustainability issues: environmental issues; location of projects; health and safety.

It should be noted that these categories are not fixed and many of the factors above are related and interchangeable. Such relations were not revealed in the questionnaire to avoid any pre-judgment/assumptions by the respondents. A major problem, which was discovered during the piloting process [31, 32], was difficulties in clarifying the meaning of offsite methods of construction to the research group. Therefore, a short description of offsite methods was included at the beginning of the questionnaire to clarify the meaning and types of offsite methods of construction.

For the purpose of attitude scaling, Likert scales 
were considered [31, 33]. Some filter questions [32] were also considered to split the respondents into two main groups of those who were and were not experienced in using offsite methods of construction. The majority of the questions were in multiple choice and closed format [31-33]. Some control questions were also introduced to achieve reliable results. The questionnaire was divided into eight main sections and aimed to investigate two main subjects:

- the current situation of the Iranian architectural profession with regards to knowledge of and experience with offsite methods of construction;

- the real and perceived risks if offsite methods were to be introduced in large scales to Iran.

\subsection{Questionnaire Distribution and Analysis}

The questionnaire was distributed among Iranian architects working at consulting companies which were selected randomly from registered architectural practices in Tehran. Thirty companies were visited and 300 questionnaires were distributed from which about 100 returned and 88 were reliable.

Around $40 \%$ of the respondents were very experienced architects with more than 10 years in practice, $15 \%$ had $6 \sim 10$ years, $32 \%$ had $3 \sim 5$ years, and the rest had 1 2 years of experience. Respondents were fairly distributed with almost all ages from $20 \sim 25$ to $50+$. Almost $47 \%$ of respondents were female and 53\% were male.

The results of the questionnaire were analyzed using SPSS (Statistical Package for the Social Sciences) and Excel software programs. Since the data were nominal and categorical, descriptive data analysis was applied using frequency and percentage. "Chi square" test was applied to examine the significance and reliability of the results. The results in $94 \%$ of cases were statistically significant to $P<0.05[31,34]$. The results presented in the text have been rounded to $\pm 1 \%$.

\section{Results}

This section reports on the results of the questionnaire analysis. Sections $\mathrm{A}, \mathrm{B}$ and $\mathrm{C}$ of the questionnaire deal with the current situation of the Iranian construction industry and evaluate the weight of the aforementioned criteria in decision making. Sections D, E and F examine the feasibility of applying offsite methods of construction in Iran by studying the attitudes of architects toward various design and construction subjects. And finally, Sections $\mathrm{G}$ and $\mathrm{H}$ study the personal attitudes of architects toward different methods of construction. The ultimate objective is to find out the most influential issues, barriers, and risks when applying offsite methods of construction to Iran.

\subsection{Section A: Considering a Method of Construction}

According to the results, the most important factor for Iranian architects when considering a method of construction is the quality of products. This was followed by the speed of construction and total costs as the second and third most important criteria (Fig. 3). Three of the five most important criteria fall into the first category (cost issues) mentioned above.

Also, the study reveals that the least important issues for Iranian architects when considering a method of construction are in descending order:

- ease of planning/building approval;

- governmental support;

- mortgage matters.

\subsection{Section B: Why Offsite}

When it comes to offsite methods, it is obvious from the results that speed of construction is the most important factor for those architects with previous experience in using these methods. Around 91\% of respondents selected the higher speed of construction as their most important criterion when considering offsite methods of construction (Fig. 4).

The least important issues for Iranian architects when considering offsite methods of construction are:

- less climate/weather dependent;

- mortgage matters; 


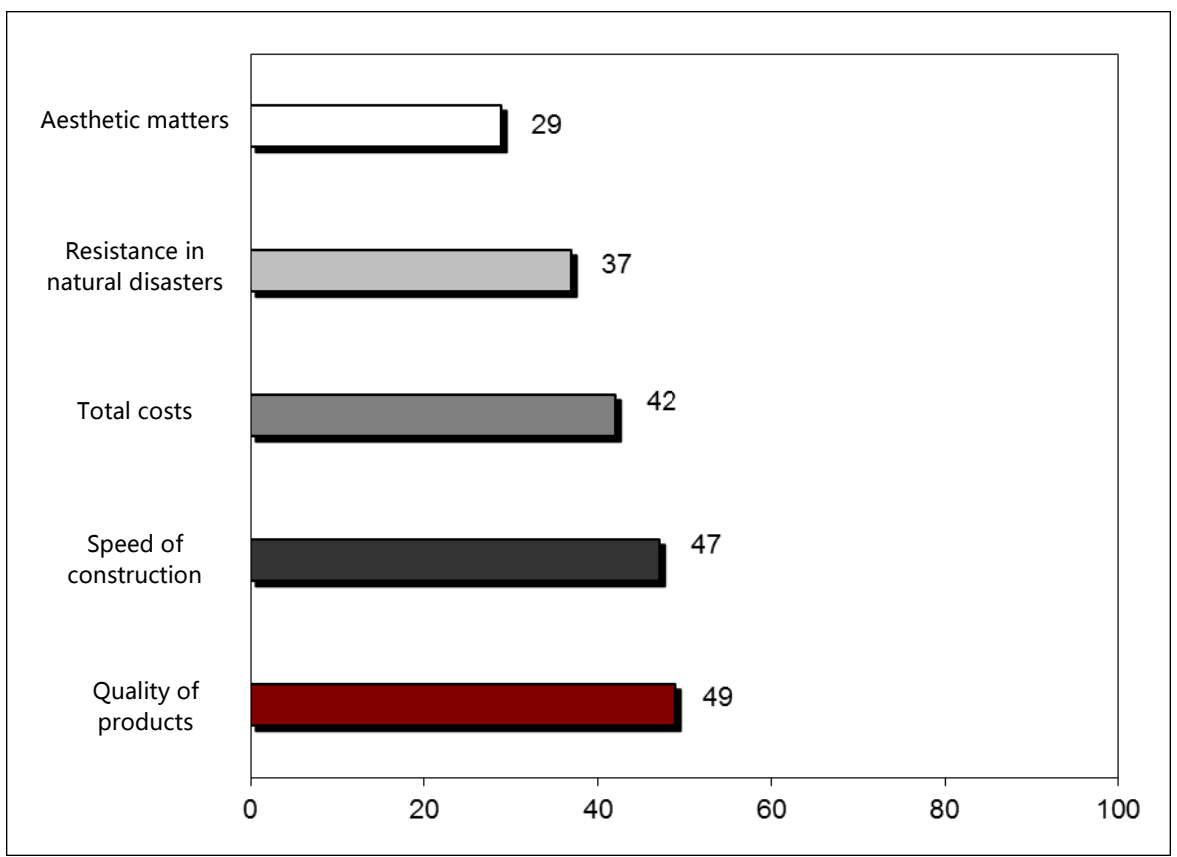

Fig. 3 Reasons for choosing a method of construction (\%).

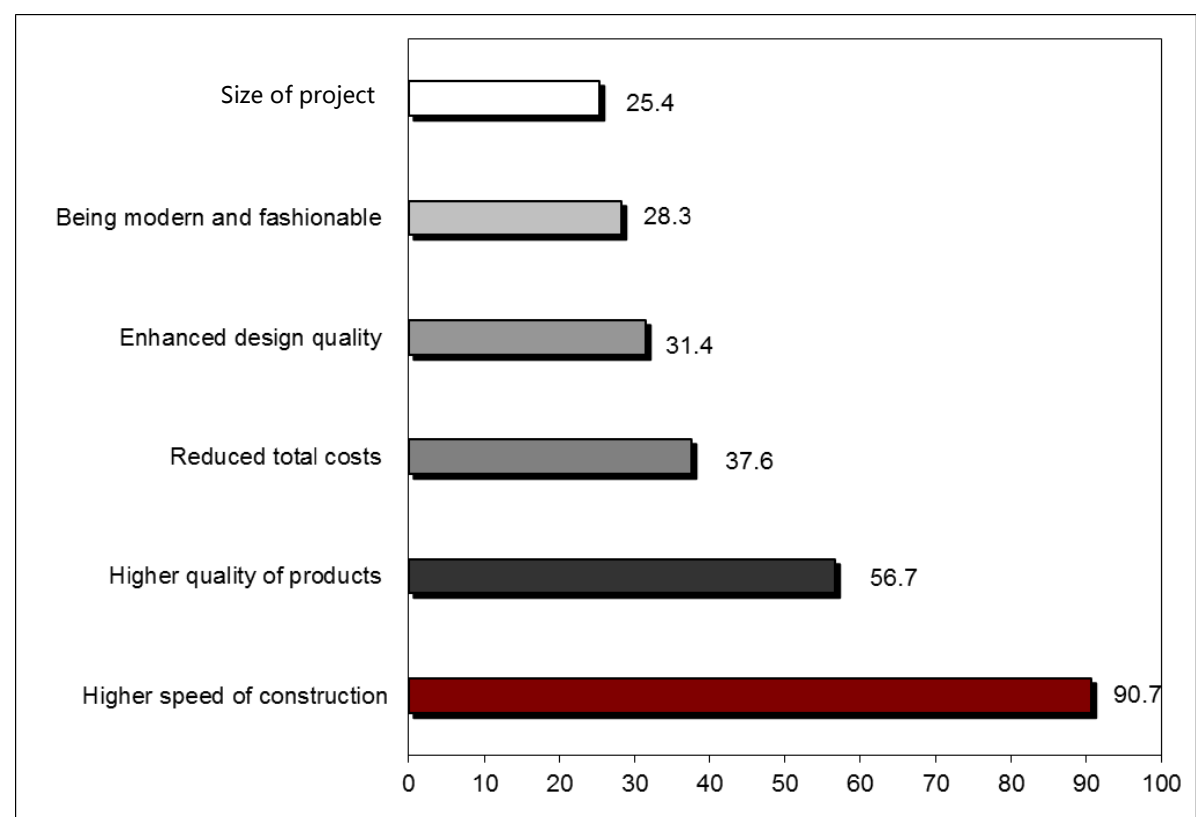

Fig. 4 Reasons for choosing offsite methods (\%).

- governmental supports;

- cultural issues.

The study also reveals that most of Iranian architects (about 56\%) are familiar with offsite methods. Almost $100 \%$ of those who were experienced in offsite methods had used panel systems and about 75\% had not used any other systems but panel systems (Fig. 5).
This means that, apart from those who had never used offsite methods (about 44\%), about $75 \%$ of the rest were not experienced in any other offsite methods. Therefore, apart from panel systems, in total, about $86 \%$ of Iranian architects are not experienced in any other offsite methods.

About $91 \%$ of architects had applied offsite methods 


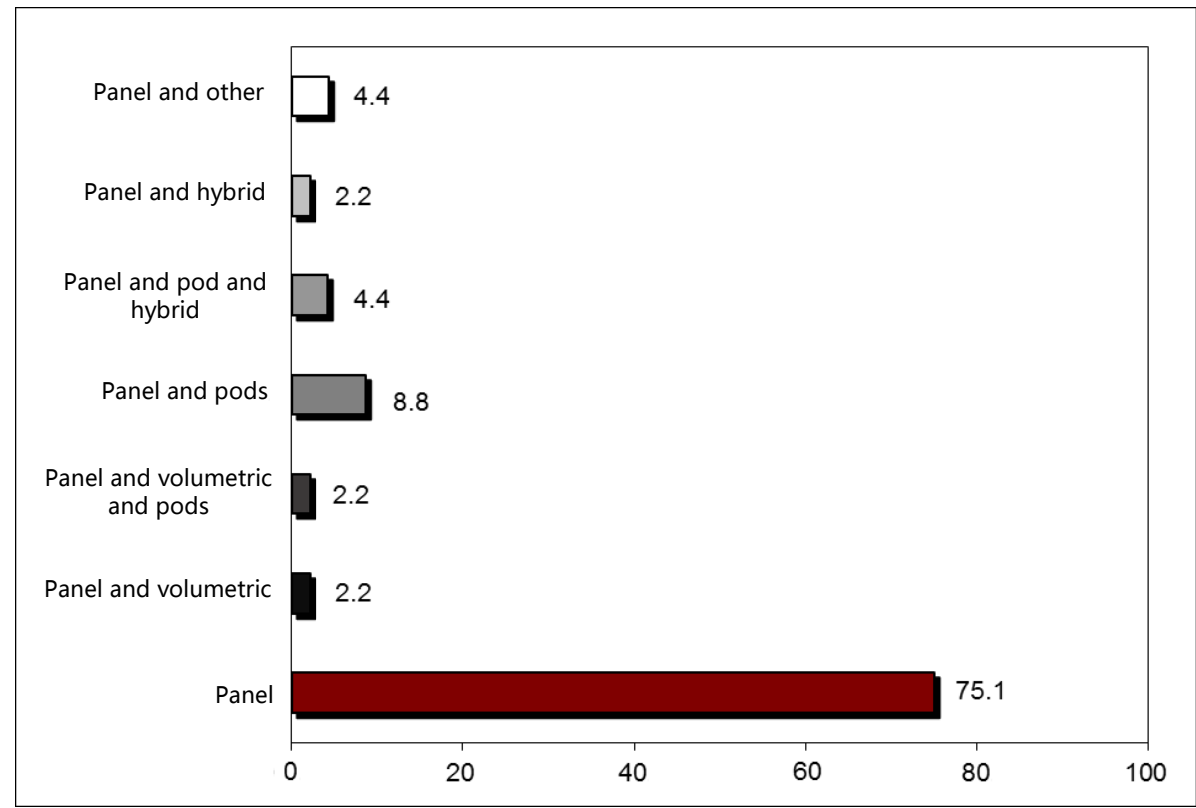

Fig. 5 Percentage of different offsite methods (\%).

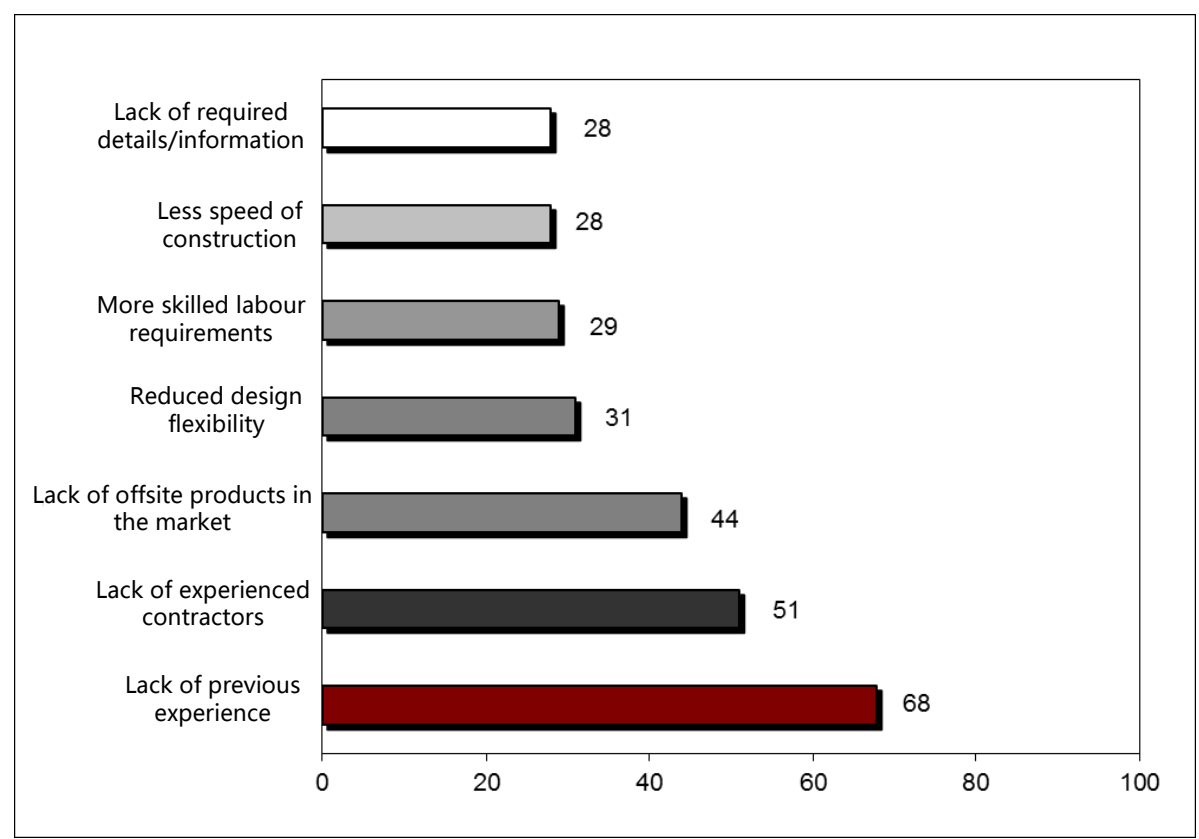

Fig. 6 Main barriers for using offsite methods (\%).

in one to five projects from which more than $64 \%$ were housing projects. Moreover, around $67 \%$ of those who were experienced in offsite methods indicated that the approximate proportion of offsite products in their housing projects was less than $25 \%$ in terms of volume. About $95 \%$ of prefabricated components used in housing projects were wall systems, 69\% floor and roof systems, $13 \%$ pods, and $0 \%$ volumetric systems.

\subsection{Section C: Why Not Offsite}

Section C mainly aimed to study the barriers toward applying offsite methods of construction in Iran. According to the results, the first three most important barriers for using offsite methods are the lack of previous experience, availability of experienced 
contractors, and availability of offsite products in the market (Fig. 6). Meanwhile, among those who had never used offsite methods, $100 \%$ indicated that they liked to apply such methods in their projects.

\subsection{Section D: Construction Methods and Industry Relationships}

The aim of this section was to study the professional relationships between Iranian architects and other stakeholders in the construction industry. It also aimed to assess the decision making processes as to when and how architects considered a method of construction.

The results reveal that 58\% of Iranian architects consider the construction methods during the outline proposal and planning stage. Also, 23\% think about the construction methods in very early stages of design. All architects consider the construction methods prior to the tender stage.

When it comes to fixing/confirming a construction method, about $53 \%$ of respondents chose the third stage of the construction process which is detailed proposals. Around 18\% indicated that building methods changed even during construction on site (Fig. 7).
The results indicate that $18 \%$ of architects ask for manufacturers' advice in very early stages and about 94\% consider manufacturers' advice before the tender stage. The results fluctuated when architects were asked about the time when they considered the contractors' advice. The figures indicate that $27 \%$ ask for contractors' advice in very late stages during construction process on site and only around 5\% consider their advice in the feasibility stage. According to the results, most of the respondents (66\%) consider structural engineers' advice in the planning stage while only $7 \%$ consult structural engineers during the feasibility stage.

The results fluctuated again when architects were asked about the professional relationship between all the bodies involved in the construction process. Around $10 \%$ of the respondents said that all or most of the stakeholders (clients, designers, engineers, contractors, and manufacturers) met during the feasibility stage and around $29 \%$ mentioned that they met during the outline proposals. Around 64\% believed that architects were the most influential people in terms of decision makings on the construction methods.

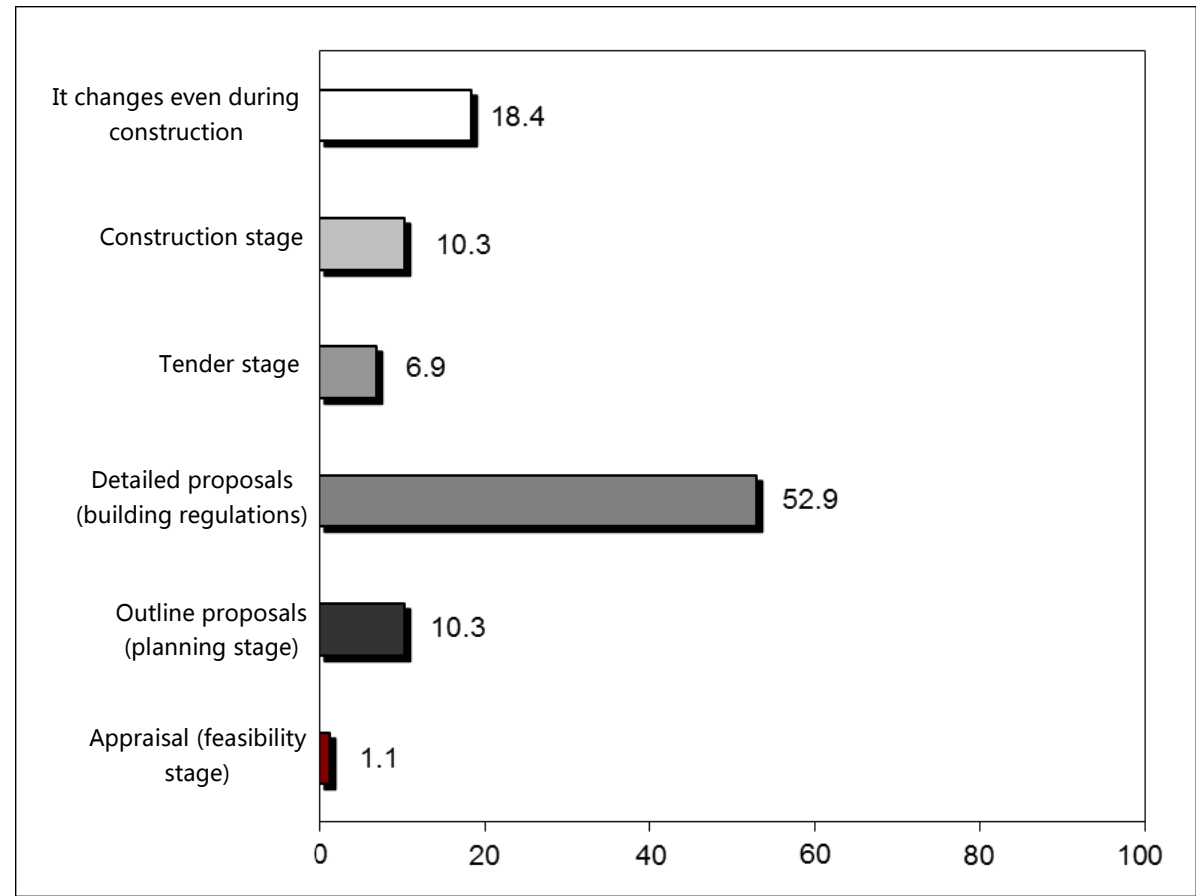

Fig. 7 The stage when construction method is fixed (\%). 
3.5 Section E: Typical Housing Projects, Types and Sizes

Section E of the questionnaire intended to study the current situation of housing projects in Tehran in terms of suitability of sizes, types, and volumes for offsite methods.

The study shows that around $80 \%$ of new housing projects designed by architects in Tehran are apartment blocks and the majority of them (about 43\%) have 6 10 residential units. About 57\% of these apartment blocks have 5 10 stories and 59\% of the residential units have an area of more than $100 \mathrm{~m}^{2}$. Regarding planning and building permissions, around $46 \%$ said that planning permission process took around 2 4 months for the majority of the projects. Around $28 \%$ said that the planning process would take even longer.

\subsection{Section F: Design Changes}

One of the major criteria, which may increase the risks of using offsite methods, is the design changes during the project [24]. This issue was studied in Section $\mathrm{F}$ of the questionnaire.

Around $55 \%$ of architects indicated that there were minor changes, 32\% believed that there were some changes, and $12 \%$ said that there were considerable changes during the project. About $70 \%$ of architects pointed that design changed even during construction process on site (Fig. 8). Architects indicated that the majority of changes occurred during the outline proposals and detailed design.

Around $49 \%$ of the respondents believed that clients and about $35 \%$ said that structural engineers were responsible for the design changes. Architects took the next place with about 33\% of respondents selecting them as the third group responsible for design changes. Also according to the results, costs, client preferences, and site issues had equal weights with around $27 \%$ of the respondents choosing them as the first common reason for design changes.

\subsection{Section G: Architects' Views on Various Construction Methods and Products}

Section G aimed to study the architects' ideas about the current situation of the Iranian construction industry in terms of various construction methods and the relevant issues to industrial production/manufacturing.

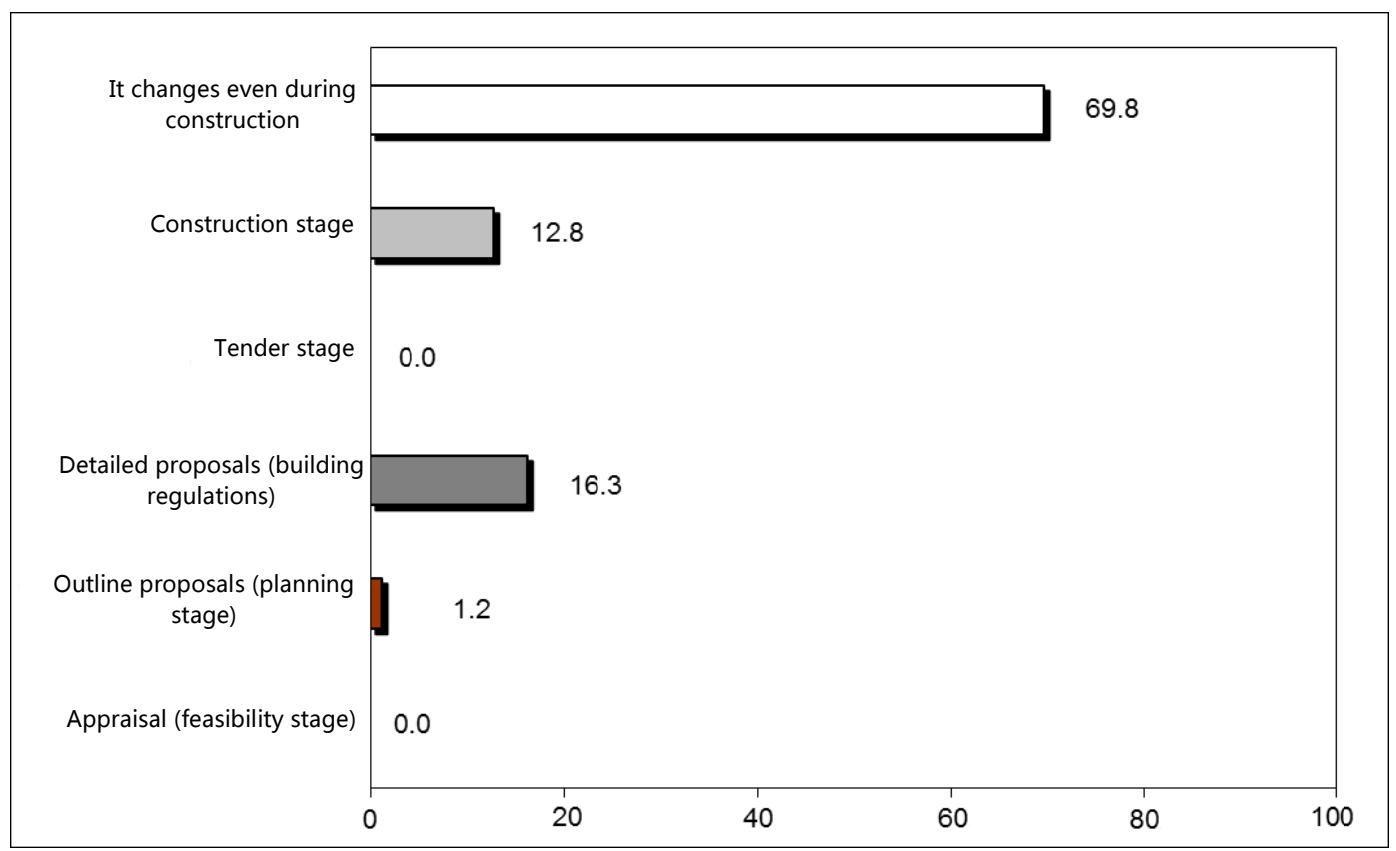

Fig. 8 Construction stage when design is fixed (\%). 
According to the results, two third of Iranian architects (66\%) preferred more familiar and reliable methods of construction. Around $63 \%$ believed that standardization would increase the design quality and $89 \%$ said that standardization would improve the construction quality.

Around $37 \%$ of respondents preferred non-Iranian products, $20 \%$ preferred Iranian products, and the rest mentioned that the source of products did not matter to them. More than half (53\%) of architects indicated that they believed that new construction methods were more stylish and only around 6\% disagreed. About $64 \%$ indicated that Iranian people/clients preferred modern looking buildings in which new methods and materials were applied.

\subsection{Section H: Architects' Views on Offsite Methods of Construction}

This section intended to evaluate and review the architects' opinions toward offsite methods of construction in more detail. To achieve accurate results, those who were not experienced in offsite methods were excluded from this section.

Regarding the total costs of offsite methods, $38 \%$ believed that they were more expensive than conventional/traditional methods of construction and $28 \%$ disagreed. Around $51 \%$ of respondents indicated that lifespan of offsite products were longer whereas $13 \%$ disagreed. Also, $60 \%$ believed that offsite products/methods had higher quality.

Almost all architects (91\%) believed that offsite methods were faster than traditional methods of construction, which confirms the findings of Section B of the questionnaire. Around $50 \%$ said that offsite methods and products were more complicated to use, and about $67 \%$ indicated that more time was required in the design stage when applying offsite methods.

About $73 \%$ mentioned that the society was showing more interest in offsite methods and $86 \%$ stated that such methods were becoming more common in the construction industry. Besides, $49 \%$ believed that there was not a huge demand for offsite methods while $40 \%$ mentioned that the current supply could not answer the demand. Almost all of the respondents (93\%) indicated that architects needed to know more about these methods. The respondents did not have a strong opinion about building insurance and financial matters involved in applying offsite methods of construction.

\section{Discussions}

The results of the questionnaire reveal several important issues which should be considered when applying offsite methods of construction in Iran. According to the results of Sections A and B of the questionnaire, when considering any method of construction (regardless of being onsite or offsite), the quality of products, speed of construction, total costs and aesthetic matters are the most important factors for Iranian architects.

Resistance against natural disasters such as earthquake should be added to the above issues. According to the received feedbacks from the respondents, the available offsite products in the market are too heavy decreasing the buildings' resistance in the event of earthquake. Moreover, heavy products require stronger structure and more material resulting in more waste and higher costs respectively. Therefore, the total weight of offsite products should be a concern when introducing these methods of construction to Iran.

Results of Sections A and B also reveal that the Iranian Government has not been very successful in encouraging architects to use offsite methods since governmental issues are of less importance to architects. Three key facts may be deduced from the results of Sections B and C of the questionnaire:

- First, Iranian architects need to be educated to know more about different offsite methods as they have very limited knowledge about these methods;

- Second, if adapted to the Iranian needs, panel systems may be more successful in Iran since almost all architects have used, or are at least aware of them and 
therefore less effort may be required to educate/encourage them to use such methods;

- Third, considering the significantly higher importance of speed, quality, and costs to Iranian architects, who are highly influential in decision making processes, it would be more effective to focus on these factors when promoting offsite methods of construction in Iran.

Project management is also a key element in successful application of offsite methods of construction. Decisions should be made and fixed in early stages of a project [30] and designers and manufacturers should be engaged in the process of decision making to choose an appropriate system $[23,30]$. Late changes may also be too costly when it comes to offsite methods of construction [20, 24]. According to the results of Section D, Iranian architects are less aware of the correct process of applying offsite methods. Moreover, according to Section F, late design changes are a normal practice which considerably increases the associated risks of applying such methods in Iran. This emphasizes the importance of educating architects, clients and other key stakeholders involved in the decision making process about the correct process of applying offsite methods and potential advantages and risks of these methods.

Continuing demand and economies of scale [35-37] are also some important issues which should be considered when applying offsite methods. Considering the results of the questionnaire, the scale of housing projects in Tehran/Iran should be questioned since it may not be economically feasible to apply offsite methods in such small projects.

Moreover, long and unclear planning processes increase the risks of methods of manufacturing [24, 30]. The planning processes should therefore be reduced and clarified to decrease the risks of application of these methods in Iran. Yet, the results of the questionnaire indicate that Iranian architects have a very positive attitude toward offsite methods of construction, which is an opportunity for such methods to be successfully adopted and applied in Iran.

\section{Conclusions}

Several advantages have been claimed for offsite methods of construction including: improved speed; improved quality; improved health and safety; improved control conditions; addressing skilled labor shortage; not weather dependent; minimized waste and energy consumption; enhanced value for money; and cost predictability.

Considering the significant housing shortages in Iran, applying offsite methods of construction can potentially improve the current situation by increasing the housing output. The results of this study, however, indicate that introducing offsite methods of construction in large industrial scales to Iran would be too risky, given the current conditions of the Iranian construction industry in general and architectural practices in particular.

It should be noted that offsite methods are considerably different from traditional methods of construction in terms of the associated risks and construction processes. Much more research is required on all abovementioned issues including costs, practicality, design, demand, policies, technology, and sustainability issues to mitigate the associated risks in order to have successful application of offsite methods in Iran. Without considering such issues, not only offsite methods fail to achieve their potential advantages over traditional methods, but also the current situation may even deteriorate. Yet, there are great opportunities for some offsite methods to be successfully adopted if the mentioned issues are considered. To this end, the Iranian Government should define a clear strategy to address the above issues and provide support and incentives for broader application of offsite methods in Iran.

\section{Further Research}

This paper intended to identify the risks and opportunities if offsite methods were to be introduced 
in large industrial scales to Iran. The focus of this study was on the attitudes and awareness of practicing architects in Tehran. The author of this study acknowledges that, although very influential, architects are only a small part of the construction industry. Therefore, similar studies should be considered to evaluate the attitudes, knowledge and awareness of other stakeholders including contractors, engineers, manufacturers, clients, material suppliers, and financial and regulatory bodies in different parts of the country in order to achieve comprehensive results identifying the key issues for successful application of offsite methods of construction in Iran.

\section{References}

[1] Buildoffsite. 2013. "Glossary of Terms 2013." Buildoffsite. Accessed August 9, 2014. http://www.buildoffsite.com/pdf/publications/BoS\%20Gl ossary\%20of\%20terms\%202013\%20\%28web\%29.pdf.

[2] Hashemi, A. 2013. "Review of the UK Housing History in Relation to System Building." Alam Cipta 6 (1): 47-58.

[3] Hashemi, A., and Hadjri, K. 2013. "Code for Sustainable Homes: Opportunities or Threats for Offsite Manufacturing and Mass-Customization?." In Proceedings of ZEMCH (Zero Energy Mass Custom Home) 2013 International Conference: The Visibility of Zero-Energy Housing, 111-22.

[4] Buildoffsite. "Buildoffsite Review 2012: The Business Case for Offsite.” Buildoffsite. Accessed August 8, 2014. http://www.buildoffsite.com/pdf/Yearbook/bos_yearbook 2012_54pp.pdf.

[5] Ross, K., Cartwright, P., and Novakovic, O. 2006. A Guide to Modern Methods of Construction. Amersham: IHE BRE Press.

[6] Hashemi, A. 2006. "Modern Methods of Construction in the UK Housing Industry." Presented at Second Research Student Conference, Cardiff, UK.

[7] SCI (Statistical Centre of Iran). 2006. Population and Housing Census 2006. Iran: SCI.

[8] SCI. 2011. National Population and Housing Census 2011. Iran: SCI.

[9] BHRC (Building \& Housing Research Center). 2009. New Construction Technologies. 5th ed.. Tehran: BHRC, Ministry of Housing and Urban Development.

[10] ICC (Iran Civil Center). 2005. "Applying New Technologies Inevitable Necessity of Housing Sector." ICC. Accessed September 14, 2013. http://www.irancivilcenter.com/fa/news/view.php?news_i $\mathrm{d}=413$.

[11] Moazen, M. 2004. Construction Industrialization Will Resolve the Low Income Housing Problems, Special News of Construction and Housing. No. 51. Iran: Iran Construction Information Centre.

[12] Fallah, M. H. 2001. "Potential Use of Light Steel Framing for Residential Building Construction in Iran." Ph.D. thesis, University of Sheffield.

[13] Fardanesh, F. 1997. "Improving the Construction Technology in Iran." In Proceedings of the First Specialized Seminar in Housing, 108-30.

[14] Sarabandi, B. 1996. "Practical Issues Mass Housing." In Proceedings of Housing Development Policies in Iran, 3rd Seminar, 777-86.

[15] Aghda, M. F. 2008. "Less Than 3\% of the Country's Construction Projects Are Industrial." Accessed November 8, 2013. http://shasa.ir/newsdetail-48201-fa. html.

[16] Saidikia, M. 2013. "Industrialized Will Reach to $20 \%$ by Year 2013." Fars News. Accessed November 21, 2013. http://www.farsnews.com/newstext.php?nn=8709040347.

[17] Hashemi, A. 2009. "Construction Technology Transfer: An Assessment of the Relevance of Modern Methods of Construction to Housing Shortages in Iran.” Ph.D. thesis, Cardiff University.

[18] Mehrim, M. R. 1998. "Lesson from Golbaft Kerman Earthquake of 14 March 1998." Presented at First Iran-Japan Workshop on Recent Earthquakes in Iran and Japan, Tehran.

[19] Amiri, S. Y. 2001. "A Study of the Production of Prefabricated Units for Industrial Building Systems in Factories in Iran." PhD thesis, University of Sheffield.

[20] Hashemi, A., and Hadjri, K. 2014. "Offsite Construction, a Potential Answer to the Iranian Housing Shortages." In Proceedings of Construction Technology and Management CTM 2014 International Scientific Conference, 189-99.

[21] Miles, J., and Whitehouse, N. 2013. "Offsite Housing Review February 2013.” Construction Industry Council. Accessed August 10, 2014. http://www.cic.org.uk/ download.php? $\mathrm{f}=$ offsite-housing-review-feb-2013-for-we b.pdf.

[22] Myers, D. 2013. Construction Economics: A New Approach. 3rd ed.. Oxon: Routledge.

[23] Burwood, S., and Jess, P. 2005. Modern Methods of Construction: Evolution or Revolution?. London: British Urban Regeneration Association.

[24] NAO (National Audit Office). 2005. Using Modern Methods of Construction to Build Homes More Quickly and Efficiently. London: National Audit Office.

[25] Hosein-nia, M. 1995. "The Method of Selection for Transferring Housing Building Technology." In 
Proceedings of Housing Development Policies in Iran, 433-7.

[26] Saadati, L. 2006. "New Technologies Cannot Be Introduced to the Construction." Accessed September 15, 2013. http://www.aftab.ir/articles/economy_marketing business/city_building/c2c1146904562_building_industry_ p1.php.

[27] Salamati, A. 2001. "Urban Housing Design in Iran: In Response to Socio-cultural and Environmental Conditions." $\mathrm{PhD}$ thesis, University of Strathclyde.

[28] Hafizi, F. 1990. "The Housing Problem in Iran.” M. Phil thesis, University College London.

[29] Rafiee, M., Yazdani, F., and Athari, K. 2003. Eghtesad-e Maskan: Educational Articles in Housing Economy. Tehran: Office of Planning and Housing Economy.

[30] CABE (Commission for Architecture and the Built Environment). 2004. Design and Modern Methods of construction, Research outcomes: 5. London: Commission for Architecture and the Built Environment.
[31] Bryman, A. 2012. Social Research Methods. 4th ed.. Oxford: Oxford University Press.

[32] Oppenheim, N. 1992. Questionnaire Design, Interviewing and Attitude Measurement. London: Printer Publishers Limited.

[33] De Vaus, D. 2002. Analyzing Social Science Data: 50 Key Problems in Data Analysis. London: Sage Publication Ltd.

[34] Sheppard, M. 2004. Appraising and Using Social Research in the Human Services. London and Philadelphia: Jessica Kingsley Publishers.

[35] Pan, W., Gibb, A., and Dainty, A. 2005. Offsite Modern Methods of Construction in Housebuilding. Loughborough: Loughborough University.

[36] Warszawski, A. 1999. Industrialized and Automated Building Systems: A Managerial Approach. 2nd ed.. London: E \& FN Spon.

[37] McEvoy, M. 1994. External Components. England: Longman, Scientific \& Technical. 